\title{
Selective Oxidative Deprotection of Trimethylsilyl Ethers in Solution and under a Solvent Free Condition
}

\author{
F. Shirini, ${ }^{*}$ M. A. Zolfigol, ${ }^{\dagger}$ I. Mohammadpoor-Baltork,,${ }^{\star}$ and M. Abedidni \\ Department of Chemistry, College of Science, Guilan University, Rasht 41335, Iran. EE-mail: shirini@guilan.ac.ir \\ ${ }^{\dagger}$ Department of Chemistry, College of Science, Bu-Ali Sina University, Hamadan 65174, Iran \\ Department of Chemistry, Isfahan University, Isfahan 81744, Iran \\ Received August 9, 2004
}

Key Words : Ammonium dichromate, Oxidative deprotection, Solvent free conditions, Trimethylsilyl ethers

Direct oxidation of trimethylsilyl ethers to their corresponding carbonyl compounds has drawn considerable attention in recent years. ${ }^{1-15}$ However, some of the reported methods suffer from disadvantages such as long reaction time, ${ }^{7,9}$ low yields of the products ${ }^{13}$ and tedious work-up procedure. $^{8}$ Therefore, introduction of new methods for such functional group transformation is still in demand.

Recently, we have reported that $\left(\mathrm{NH}_{4}\right)_{2} \mathrm{Cr}_{2} \mathrm{O}_{7}$ in the presence of $\mathrm{Al}\left(\mathrm{HSO}_{4}\right)_{3}$ and wet $\mathrm{SiO}_{2}$ can be used as an efficient reagent for the oxidation of alcohols to their corresponding carbonyl compounds. ${ }^{16}$ In continuation of this study, we were interested in extending the applicability of this reagent system to the oxidation of the other functional groups. In this paper, we report a new, efficient and selective method for the oxidative deprotection of trimethylsilyl ethers to their corresponding carbonyl compounds using the above mentioned reagent system in solution and under a solvent free condition. Oxidative deprotection of different types of trimethylsilyl ethers was investigated in the absence of solvent with ammonium dichromate in the presence of $\mathrm{Al}\left(\mathrm{HSO}_{4}\right)_{3}$ and wet $\mathrm{SiO}_{2}$ at room temperature (Scheme 1).

Yields and reaction times are given in Table 1. Benzylic trimethylsilyl ethers, including electron donating and withdrawing groups are converted to their corresponding carbonyl compounds in high yields (Table 1). Trimethylsilyl ethers containing alkyl ethereal groups are converted to their corresponding aldehydes and ketones without cleavage of carbon-oxygen bond (Table 1, entries 9, 10). This method is also very effective for the oxidation of non-benzylic trimethylsilyl ethers (Table 1, entries 13-16). Over-oxidation of the products was not observed by this method. In order to compare the results obtained under a solvent free condition with those obtained in solution, we studied the oxidation reaction in $n$-hexane. As shown in Table 1 , in most cases, there are appreciable differences between the results obtained in solution and those under a solvent free condition. By omitting the solvent, the reaction time was reduced in

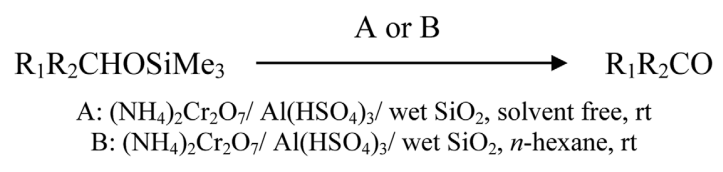

Scheme 1 addition to ease of the work-up procedure. It should be noted that the oxidation did not proceed using any of $\mathrm{Al}\left(\mathrm{HSO}_{4}\right)_{3}$, ammonium dichromate or wet $\mathrm{SiO}_{2}$ alone, which presumably suggested the in situ generation of $\mathrm{H}_{2} \mathrm{CrO}_{4}$ in low concentration at the surface of wet $\mathrm{SiO}_{2}$ by the solid inorganic acid salts $\mathrm{Al}\left(\mathrm{HSO}_{4}\right)_{3}$ and $\left(\mathrm{NH}_{4}\right)_{2} \mathrm{Cr}_{2} \mathrm{O}_{7}$.

Tetrahydropyranyl ethers do not undergo oxidative deprotection by this method. Therefore, in order to show the selectivity of the described method, we have also performed competitive oxidative deprotection reactions. The experimental results show that trimethylsilyl ethers are oxidized selectively in the presence of tetrahydropyranyl ethers (Scheme 2). These selectivities are useful achievements in organic synthesis.

In conclusion, we have introduced a mild, efficient and selective method for the selective oxidative deprotection of trimethylsilyl ethers using ammonium dichromate in the presence of $\mathrm{Al}\left(\mathrm{HSO}_{4}\right)_{3}$ and wet $\mathrm{SiO}_{2}$ in solution and under a solvent free condition.

\section{Experimental Section}

General: Trimethylsilyl and tetrahydropyranyl ethers and $\mathrm{Al}\left(\mathrm{HSO}_{4}\right)_{3}$ were prepared according to the literature procedures. ${ }^{17,18,19}$ All oxidation products are known compounds; they are identified by comparison of their physical data, IR and NMR spectra with those of authentic samples. Yields refer to isolated products or their 2,4-dinitorphenylhydrazones.

Oxidative deprotection of trimethylsilyl ethers under a solvent free condition. General procedure: The substrate (1 mmol) was added to a mixture of $\left(\mathrm{NH}_{4}\right)_{2} \mathrm{Cr}_{2} \mathrm{O}_{7}(0.75$ mmol, $0.189 \mathrm{~g}), \mathrm{Al}\left(\mathrm{HSO}_{4}\right)_{3}(0.75 \mathrm{mmol}, 0.237 \mathrm{~g})$ and wet $\mathrm{SiO}_{2}\left[\left(\mathrm{SiO}_{2} / \mathrm{H}_{2} \mathrm{O}: 50 \%\right.\right.$ wt $\left.), 0.1 \mathrm{~g}\right]$ The resultant mixture was stirred at room temperature for the specified time (Table 1). The progress of the reaction was monitored by GC or TLC. The reaction mixture was triturated with $\mathrm{CH}_{2} \mathrm{Cl}_{2}(10 \mathrm{~mL})$ and then filtered. Anhydrous $\mathrm{MgSO}_{4}$ was added to the filtrate and the mixture was filtered after $10 \mathrm{~min}$. The filtrate was evaporated on a rotary evaporator and the resulting crude material was purified on a silica gel plate or silica gel column with appropriate eluents. Pure carbonyl compounds were obtained in $85-95 \%$ yields (Table 1 ). 
Table 1. Oxidative deprotection of trimethylsilyl ethers

\begin{tabular}{|c|c|c|c|c|c|c|}
\hline \multirow{2}{*}{ Entry } & \multirow{2}{*}{ Substrate } & \multirow{2}{*}{ Product } & \multicolumn{2}{|c|}{ Solvent free oxidation } & \multicolumn{2}{|c|}{ Oxidation in solvent } \\
\hline & & & Time (min) & Isolated Yield \% & Time (min) & Isolated Yield \% \\
\hline 1 & & & 10 & 95 & 10 & 90 \\
\hline 2 & & & 15 & 95 & 20 & 85 \\
\hline 3 & & & 15 & 92 & 180 & 80 \\
\hline 4 & & & 15 & 90 & 50 & 85 \\
\hline 5 & & & 20 & 95 & 180 & 82 \\
\hline 6 & & & 45 & 90 & 180 & 85 \\
\hline 7 & & & 10 & 90 & 35 & 85 \\
\hline 8 & & & 15 & 88 & 150 & 80 \\
\hline 9 & & & 15 & 90 & 180 & 85 \\
\hline 10 & & & 20 & 92 & 120 & 60 \\
\hline 11 & & & 20 & 95 & 30 & 90 \\
\hline 12 & & & 20 & 90 & 35 & 80 \\
\hline 13 & & & 10 & 85 & 40 & 82 \\
\hline 14 & & & 15 & 95 & 120 & 60 \\
\hline 15 & & & 40 & 90 & 130 & 80 \\
\hline 16 & & & 45 & 95 & 150 & 85 \\
\hline
\end{tabular}


<smiles>COCc1ccccc1Cl</smiles><smiles>COCc1cccc(OC)c1</smiles>

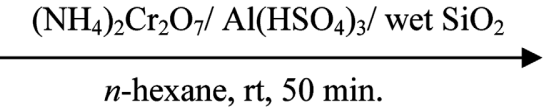
n-hexane, rt, $50 \mathrm{~min}$.<smiles>O=Cc1ccccc1Cl</smiles>

100 (conversion)<smiles>COc1cccc(C=O)c1</smiles>

100 (conversion)<smiles>CC(C)(C)c1ccc(C=O)cc1</smiles>

0 (conversion)<smiles>O=Cc1ccc([N+](=O)[O-])cc1</smiles>

0 (conversion)

Scheme 2

\section{Oxidation of trimethylsilyl ethers in $\boldsymbol{n}$-hexane. General} procedure: In a round-bottomed flask $(20 \mathrm{~mL})$ equipped with a magnetic stirrer a suspension of $\left(\mathrm{NH}_{4}\right)_{2} \mathrm{Cr}_{2} \mathrm{O}_{7}(0.75$ mmol, $0.189 \mathrm{~g}), \mathrm{Al}\left(\mathrm{HSO}_{4}\right)_{3}(0.75 \mathrm{mmol}, 0.237 \mathrm{~g})$ and wet $\mathrm{SiO}_{2}\left[\left(\mathrm{SiO}_{2} / \mathrm{H}_{2} \mathrm{O}: 50 \%\right.\right.$ wt. $\left.\left.), 0.1 \mathrm{~g}\right)\right]$ in $n$-hexane $(5 \mathrm{~mL})$ was prepared. The substrate $(1 \mathrm{mmol})$ was added to the mixture and stirred at room temperature for the specified time (Table 1). The progress of the reaction was monitored by GC or TLC. The mixture was filtered and the solid material was washed with $\mathrm{CH}_{2} \mathrm{Cl}_{2}(10 \mathrm{~mL})$. The filtrate was evaporated on a rotary evaporator and the resulting crude material was purified on a silica gel plate or silica gel column with appropriate eluents. Pure carbonyl compounds were obtained in 60-90\% yields (Table 1).

Acknowledgement. Financial support of this work by the Guilan University Research Council is gratefully acknowledged.

\section{References}

1. Greene, T. W.; Wuts, P. G. Protective Groups in Organic Synthesis, $3^{\text {rd }}$ ed.; John Wiley \& Sons Inc.: New York, 1991.
2. Lalonde, M.; Chan, T. H. Synthesis 1985, 817, and references cited therein.

3. Muzart, J. Synthesis 1993, 11, and references cited therein.

4. Mohammadpoor-Baltork, I.; Pouranshirvani, S. Synth. Commun. 1996, 26, 1.

5. Baker, R.; Rao, V. B.; Ravenscroft, P. D.; Swain, C. J. Synthesis 1983, 572 .

6. Mahrwald, R.; Theil, F.; Schick, H.; Schwartz, S.; Palme, H. J.; Weber, G. J. Prakt. Chem. 1986, 328, 777.

7. Muzart, J.; N'Ait Ajjou, A. Synlett 1991, 497.

8. Olah, G. A.; Gupta, B. G. B.; Fung, A. P. Synthesis 1980, 897.

9. Muzart, J.; N'Ait Ajjou, A. Synth. Commun. 1992, 22, 1993.

10. Firouzabadi, H.; Mohammadpoor-Baltork, I. Synth. Commun. 1994, 24, 1065.

11. Jung, M. E. J. Org. Chem. 1976, 41, 1479.

12. Tolstikov, G. A.; Miftakhov, M. S.; Alder, M. E.; Komissarova, N. G.; Kuznetsov, O. M.; Vostrikov, N. S. Synthesis 1989, 940.

13. Pinnik, H. W.; Lajis, N. H. J. Org. Chem. 1978, 43, 371.

14. Firouzabadi, H.; Shirini, F. Synth. Commun. 1996, 26, 423.

15. Firouzabadi, H.; Shirini, F. Synth. Commun. 1996, 26, 649.

16. Shirini, F.; Zolfigol, M. A.; Abedini, M.; Salehi, P. Mendeleev Commun. 2003, 265.

17. Maity, G.; Roy, S. C. Synth. Commun. 1993, 23, 1667.

18. Neville, G. J. Org. Chem. 1960, 25, 1063.

19. Shirini, F.; Zolfigol, M. A.; Abedini, M.; Salehi, P. Bull. Korean Chem. Soc. 2003, 24, 1683. 